\title{
Maternity and Childcare Domain of Women in Medical Profession
}

\author{
Shylasree TS ${ }^{1}$ Rohini Kulkarni ${ }^{1} \quad$ Lavanya Gurram ${ }^{2}$
}

${ }^{1}$ Department of Gynaecological Oncology, Tata Memorial Centre,
Homi Bhabha National Institute, Mumbai, Maharashtra, India
2 Department of Radiation Oncology, Tata Memorial Centre, Homi
Bhabha National Institute, Mumbai, Maharashtra, India

Ind J Med Paediatr Oncol 2022;43:12-14.
Address for correspondence Shylasree TS, MD, FRCOG, Department of Gynaecological Oncology, Tata Memorial Centre, Homi Bhabha National Institute, Mumbai, Maharashtra 400012, India (e-mail: shyla_sree@hotmail.com).

\section{Introduction}

Globally, maternity and childcare has been a serious issue for women in the reproductive age group belonging to any socioeconomic strata with any educational background. Despite this obvious observation in society, the elephant in the room has been ignored for centuries. The subject of maternity and childcare in the lives of women health care professionals (WHP) is compelling for discussion, since the last two decades have witnessed a progressive trend in the representation of women in the medical profession. Over $50 \%$ of undergraduate medical students in India are girls, ${ }^{1}$ leading to a substantial increase in the female medical workforce in hospitals and communities working as residents or junior consultants in their reproductive years. Many developed nations have addressed maternity and childcare issues at a policy level for all professions which has given immense support to families with pregnant women and young children. However, such policies are not uniform globally and they are definitely suboptimal in developing and underdeveloped countries. Maternity and childcare issues can act as major deterrents in pursuing a successful and fulfilling medical profession which in turn lead to loss of human resources, skills, and intellectual contribution.

In this article, we have highlighted maternity and child care concerns with a special emphasis on India and draw attention toward the need to act and bring in comprehensive policies for women in health care.

\section{Rules and Regulations: Comparisons}

In India, the Maternity Benefit (Amendment) Act 2017 states that working women are entitled to paid maternity leave for

DOI https://doi.org/ $10.1055 / \mathrm{s}-0042-1742659$. ISSN 0971-5851.
26 weeks which includes a pre-natal leave of 8 weeks, provided the woman has worked as an employee for a minimum period of 80 days in the last 12 months. ${ }^{2}$ In the United Kingdom, pregnant working women are entitled to 52 weeks (1 year) of maternity leave, irrespective of the duration of work with her employer. Also, parents of children aged 16 years and under, or of disabled children aged 18 years and under, are entitled to request a flexible working pattern. ${ }^{3}$ In the United States, Family and Medical Leave Act, 1993 legal parents are protected for up to 12 weeks of unpaid leave (per year). ${ }^{4}$ This is below the 14 to 18 weeks minimum recommended by the World Health Organization as per International labor organization laws. ${ }^{5}$ Maternity leave in Japan covers a period of 6 weeks prior to the expected birth date to 8 weeks after giving birth. Child care leave (CCL) applies to both female and male employees which can extend to a period of one year. During this period, the employee salary will be covered by the social/labor insurance up to a limit of around two-third of the base salary. ${ }^{6}$

\section{Current Situation in India}

\section{Family Planning and Pregnancy Perspectives}

The demands of undergraduate training and study preparation times for postgraduate entrance exams do not allow WHP to envisage family planning. The tough grind of residency programs deters WHP to plan pregnancy. The outlook of colleagues and teachers toward pregnancy during residency is often cynical. The average age a woman enters super-specialty training is 30 years. Beyond this age, fertility concerns arise and hence most women are compelled to conceive during their residency. In addition, familial and
(C) 2022. Indian Society of Medical and Paediatric Oncology. All rights reserved.

This is an open access article published by Thieme under the terms of the Creative Commons Attribution-NonDerivative-NonCommercial-License, permitting copying and reproduction so long as the original work is given appropriate credit. Contents may not be used for commercial purposes, or adapted, remixed, transformed or built upon. (https://creativecommons.org/ licenses/by-nc-nd/4.0/)

Thieme Medical and Scientific Publishers Pvt. Ltd., A-12, 2nd Floor, Sector 2, Noida-201301 UP, India 
social pressures complicate the situation. Planning a pregnancy immediately post-residency puts the WHP at the risk of losing consultant positions to male counterparts, especially in the private sector wherein profit measures are uncompromising and personal questions regarding the status of marriage and children are probed during interviews. There is sufficient information to establish that female doctors not only lose income during maternity and child care but also have significant professional dissatisfaction, especially for those involved in procedural specialties. ${ }^{7}$ In some of the recent surveys published regarding gender equality among oncologists, close to $64 \%$ of the respondents believed that their gender had an impact on their career, $58 \%$ reported problems finding a work-life balance. ${ }^{8,9}$ There are social media surveys reporting close to $50 \%$ women oncologists facing workplace bullying, harassment, and gender bias which may contribute to inequality in academia. ${ }^{10-12}$ On the flip side, it has been reported that female medical professionals "prioritize career advancement by delaying starting a family" and that female doctors believed that "career progression would be slowed by motherhood."13 Challenges faced by women in developing countries are mainly workplace stress and deficiencies in addressing the needs of pregnant women. ${ }^{14}$ In addition to the above, strong centurial socio-cultural standards toward woman's home/work-related roles and responsibilities in India put WHP in extreme pressures. Lack of legal knowledge, conflicting reports in newspapers, and social media compounds fear of losing jobs and majority prefer to endure everything in silence. This has a deep impact on the physical and emotional wellbeing, in addition to miscarriages and pregnancy-related complications. This is compounded by the ever-surmounting issues related to fertility, maternal, and neonatal complications of pregnancy with advanced maternal age.

\section{Maternity Leave}

India does offer significant maternity benefits in the form of paid maternity leave for a period of 26 weeks for all those who have completed 80 days of work in the previous calendar year. In addition, women employees having minor children may be granted CCL by an authority competent to grant leave for a maximum period of 2 years (i.e., 730 days) during their entire service for taking care of up to two minor children whether for rearing or to look after any of their needs like examination, sickness, etc. ${ }^{15}$ However, the majority of private sectors are not attached to the aforementioned regulations in entirety due to further clauses in contract agreements and powerful corporate legal terms. Another caveat is that the majority of resident population is not eligible to avail this "benefit" as per the state Medical Council of India regulations since they are not considered employees. ${ }^{16}$ Most universities consider residents as students and deprive them of the benefits of an employee. They also penalize them in the form of course extensions without pay and do not allow them to appear for timely examinations. In addition, non-service postgraduates may not receive their maternity leave benefits, as they are not regularized employees. ${ }^{17}$

Disappointment and frustration of these medical professionals can be reflected in the number of litigations filed with respect to maternity benefit issues. Consistently, the judiciary of our country has backed female medical professionals by stating that female medical residents are entitled to all maternity benefits as per law. ${ }^{18,19}$ Despite this, it is predominantly ignored by the institutional administration policymakers.

\section{Breast Feeding}

Exclusive breast feeding for the first 6 months is advocated on a stringent note in India. Lactation for extended periods is encouraged. Duration of breast feeding in medical professionals depends on the duration of maternity leave, work hours, travel distance to workplace, lack of facilities for expressing, and storing breast milk at workplace. Dependence on formula feeds is increasing due to myriad difficulties. In addition, "the doctor knowledge" and inability to provide as per one's expectations after resuming work increase the guilt which also has an impact on milk production in a new mother.

\section{Child Upbringing}

In India, the primary responsibility of childrearing and household falls on the mother irrespective of her employment status. The onus of tending to the sick in hospitals in addition to minimally supported childcare at home renders a woman professional at odds continually. The existential heterogeneity in the modernizing family system of the sub-continent poses a challenge to compare or deduce impressions. With job opportunities away from hometowns, the probability of getting help from extended family for longer durations is becoming minimal. The Maternity Benefit Amendment Act makes the crèche facility mandatory for every establishment employing 50 or more employees with a provision of visiting crèche four times during the day. ${ }^{2}$ Despite this, crèches at the workplace are a rarity even in large institutions due to "supposed prioritizations" in lieu of lack of space and funds. Prolonged work hours lead to separation anxiety in WHP and lead to burnout and depression, which are unattended. This leads to work-family conflicts which have a negative bearing on career and marital lives. The majority of WHP in India depend on housemaids who function as nannies, in contrast to the developed world wherein strict mandatory qualifications are required for a nanny's post. Day-care centers are increasingly becoming available and, however, are fraught with logistic problems of drop-ins and pickups due to the difference in operating hours (WHP vs. day-care timings). The employer almost always wishes to be oblivious of stresses faced by WHP, who, on the contrary, do not wish to be considered weaklings and refrain from broaching the subject.

In western countries, WHP try to balance work and child upbringing by doing part-time and flexible hour jobs. With no such available option in India, WHP are at a loss with no choice except to continue working in an unfriendly atmosphere or quit the job. This is a common occurrence in many countries. ${ }^{20}$ Gender disparities, rising gap over the years, and impact on leadership roles are a debate beyond the scope of this script. The nightmare continues when WHP who wish to 
re-join workforce are faced with the interrogation of reasons for gap/s and competence concerns. Despite multiple roadblocks, job satisfaction and work deliverance are high among WHPs. Academic and research pursuits require more hours which add to the strain and constant self-comparison to peers with higher productivity causing further demoralization.

It is crucial to understand that the emotional wellbeing of a mother is imperative for a happy childhood. It is indeed a shocking revelation for a country of this magnitude to have nearly nil literature including surveys and reports in this regard.

In situations such as the COVID-19 pandemic, the stress is heightened with minimal to no support for child care especially with online classrooms, lack of house help, and women being forced to take extended leaves with the risk of losing their jobs.

\section{Future Directions}

It is overdue to address maternity and childcare issues among WHPs especially in their residency and early careers. There should be a comprehensive policy that includes residents and gives them employee status with due benefits. Institutional administration (government/private) should be more considerate and empathetic toward women health professionals who are the backbone of health care system and to avoid immense deficit in taskforce in coming decades. Flexible hours and parttime options (including tele-consultation facilities) should be made available to ensure smooth transitioning into the role of motherhood without biases. Crèche and off-hour care facilities must be considered mandatory for better wellbeing, work satisfaction, and productivity.

\section{Conflict of Interest}

None declared.

\section{References}

1 Chakraborty R. Maha sees drop in percentage of women taking up medical courses. Hindustan Times. Published March 8, 2020. Accessed November 1, 2021 at: https://www.hindustantimes. com/cities/maha-sees-drop-in-percentage-of-women-takingup-medical-courses/story-LQvQ9kWS3xJ5dQCyRUocvJ.html

2 Ministry of Labour and Employment. Maternity Benefit amendment act, 2017. Published on April 5, 2017. Accessed November 1, 2021 at: https://labour.gov.in/whatsnew/maternity-benefitamendment-act2017

3 National Health Service (NHS) Maternity and paternity benefits and leave. Published on April 20, 2021. Accessed November 1, 2021 at: https://www.nhs.uk/pregnancy/finding-out/maternityand-paternity-benefits-and-leave/
4 U.S. Department of Labour. "Wage and Hour Division (WHD): Family and Medical Leave Act". Published on September 4, 2018. Accessed November 1, 2021 at: https://www. dol.gov/agencies/whd/fmla

5 World Health Oragnisation. NLiS. Maternity protection: Compliance with international labor standards. https://www.who.int/ data/nutrition/nlis/info/maternity-protection-compliancewith-international-labour-standards Accessed November 1, 2021.

6 JMC Japan payroll and benefits. Japan Maternity and Childcare Leave. Accessed November 1, 2021 at: http://japan-payroll.com/japan-maternity-leave/

7 Scully RE, Davids JS, Melnitchouk N. Impact of procedural specialty on maternity leave and career satisfaction among female physicians. Ann Surg 2017;266(02):210-217

8 Salem R, Haibe Y, Dagher C, et al. Female oncologists in the Middle East and North Africa: progress towards gender equality. ESMO Open 2019;4(03):e000487

9 Banerjee S, Dafni U, Allen T, et al. Gender-related challenges facing oncologists: the results of the ESMO Women for Oncology Committee survey. ESMO Open 2018;3(06):e000422

10 Lawrence, Ryan. Survey: Most female gynecologic oncologists have faced workplace bullying, harassment. HEM/ONC Today; Thorofare 2021;22(5):20-21

11 Beeler WH, Griffith KA, Jones RD, et al. Gender, professional experiences, and personal characteristics of academic radiation oncology chairs: data to inform the pipeline for the 21st century. Int J Radiat Oncol Biol Phys 2019;104(05):979-986

12 Jagsi R, Griffith KA, Jones R, Perumalswami CR, Ubel P, Stewart A. Sexual harassment and discrimination experiences of academic medical faculty. JAMA 2016;315(19):2120-2121

13 Hoffman R, Mullan J, Nguyen M, Bonney AD. Motherhood and medicine: systematic review of the experiences of mothers who are doctors. Med J Aust 2020;213(07):329-334

14 ALobaid AM, Gosling CM, Khasawneh E, et al. Challenges faced by female healthcare professionals in the workforce: a scoping review. J Multidiscip Healthc 2020;13:681-691

15 7th Pay Commission report on child care leave for central government employees. Issued on June 5, 2014. Accessed November 1, 2021 at: https://7thpaycommissionnews.in/child-care-leave-detailed-questions-and-answers/

16 TNN. Resident doctors demand maternity leave in the state. Times of India. Published on September 11, 2018. Accessed November 1, 2021 at: https://timesofindia.indiatimes.com/city/ mumbai/resident-doctors-demand-maternity- leave-in-state/ articleshow/65760465.cms

17 Josephine MS. Without regularization, doctors denied maternity leave benefits. Published on September 26, 2021. Accessed November 1, 2021 at: https://www.thehindu.com/news/national/tamilnadu/without-regularisation-doctors- denied-maternity-leavebenefits/article36676005.ece

18 High court of Delhi. Pronounced on February 1, 2019. Accessed November 1, 2021 at: https://www.livelaw.in/pdf_upload/pdf upload-358021.pdf

19 Central administrative tribunal-Delhi Published on August 12, 2015. Accessed November 1, 2021 at: https://indiankanoon.org/ doc/75945949/

20 Frank E, Zhao Z, Sen S, Guille C. Gender disparities in work and parental status among early career physicians. JAMA Netw Open 2019;2(08):e198340 